DOI: https://doi.org/10.47405/mjssh.v6i6.833

\begin{tabular}{|c|c|}
\hline 4 & Malaysian Journal of Social Sciences and Humanities (MJSSH) \\
\hline $\begin{array}{l}\text { Malaysian Juoural of } \\
\text { Social ccciecces and }\end{array}$ & Volume 6, Issue 6, June 2021 \\
\hline (MJ-sSH) & e-ISSN : 2504-8562 \\
\hline & $\begin{array}{l}\text { Journal home page: } \\
\text { www.msocialsciences.com }\end{array}$ \\
\hline
\end{tabular}

\title{
Sikap dan Motivasi Pelajar Terhadap Kemahiran Berfikir Aras Tinggi dalam Pembelajaran Bahasa Iban
}

\author{
Rosita Kunyo', Ruhizan Mohammad Yasin'1 \\ ${ }^{1}$ Fakulti Pendidikan, Universiti Kebangsaan Malaysia (UKM) \\ Correspondence: Rosita Kunyo (rositakunyo@yahoo.com)
}

\begin{abstract}
Abstrak
Kemahiran berfikir aras tinggi (KBAT) telah menjadi keutamaan dalam pembelajaran masa kini khususnya dalam penyoalan dalam pengajaran dan peperiksaan. Bahasa Iban pula merupakan salah satu mata pelajaran yang mengangkat bahasa ibunda sebagai bahasa ilmiah. Namun, penguasaan KBAT pelajar dalam Bahasa Iban masih berada pada tahap yang lemah. Kajian ini bertujuan untuk mengenal pasti sikap pelajar terhadap KBAT dalam pembelajaran Bahasa Iban berdasarkan faktor jantina, bangsa dan sekolah serta hubungannya dengan motivasi intrinsik dan ekstrinsik. Seramai 240 orang pelajar dari empat buah sekolah menengah di daerah Simunjan, Sarawak telah terlibat sebagai responden. Kajian ini menggunakan pendekatan kuantitatif di mana satu set soal selidik digunakan untuk mendapatkan data kajian yang kemudiannya dianalisis menggunakan SPSS versi 25. Dapatan kajian menunjukkan tidak terdapat perbezaan yang signifikan sikap pelajar lelaki dan pelajar perempuan terhadap KBAT dalam pembelajaran Bahasa Iban. Keputusan ujian ANOVA sikap pelajar berdasarkan kaum juga menunjukkan tidak terdapat perbezaan yang signifikan skor min sikap pelajar terhadap KBAT dalam pembelajaran Bahasa Iban berdasarkan kaum mereka. Dari aspek sekolah juga menunjukkan tidak terdapat perbezaan yang signifikan skor min sikap pelajar terhadap KBAT dalam pembelajaran Bahasa Iban berdasarkan faktor sekolah yang mereka wakili. Keputusan ujian Korelasi pula menunjukkan terdapat hubungan yang signifikan antara motivasi intrinsik dan ekstrinsik dengan sikap pelajar terhadap KBAT dalam pembelajaran Bahasa Iban. Berdasarkan dapatan kajian, dapatlah dirumuskan bahawa sikap dan motivasi terhadap KBAT perlu diterapkan agar pelajar dapat mengoptimumkan penggunaan minda sekali gus mengaplikasikan pengetahuan dan kemahiran dalam kehidupan.
\end{abstract}

Kata kunci: sikap, motivasi intrinsik, motivasi ekstrinsik, KBAT, Bahasa Iban

\section{Attitude and Students' Motivation towards Higher Order Thinking Skills in Learning Iban Language Subject}

\begin{abstract}
Higher Order Thinking Skills (HOTS) has become a priority in today's learning especially in questioning strategies used in teaching and assessment. Meanwhile, the Iban Language is a subject that uplifts native language to be an academic language. However, the students' mastery towards HOTS in any given subject is still at a low level. This study is intended to identify students' attitude towards HOTS in the learning of Iban Language subject based on gender, ethnicity and school and the correlation with intrinsic and extrinsic motivation. There are 240 students from four secondary schools
\end{abstract}


in Simunjan district in Sarawak involved as respondents in this study. This study uses quantitative approach which has one set of questionnaires and is used to obtain data which analysed using SPSS version 25. Based on the study findings, there are no significant differences of attitude between male and female students towards HOTS in the learning of Iban Language subject. ANOVA test result on students' attitude based on ethnicity does not show significant difference of min score on the study matter. From the school aspect, there is no significant difference in the mean score of students' attitude towards HOTS in Iban language learning based on the school factors they represent. However, Correlation Test result shows a significant relation between intrinsic and extrinsic motivation with students' attitude towards HOTS in the learning of Iban Language. Based on study findings, it can be concluded that attitude and motivation on HOTS need to be applied in order for the students to be able to optimise mind usage and at the same time apply the knowledge and skills in life.

Keywords: attitude, intrinsic motivation, extrinsic motivation, HOTS, Iban Language

\section{Pengenalan}

KBAT merupakan konsep awal yang dimulakan daripada objektif pendidikan Taksonomi Bloom (Bloom et al., 1956). Taksonomi Bloom merangkumi enam aras domain kognitif iaitu pengetahuan, pemahaman, aplikasi, analisis, sintesis dan penilaian. Taksonomi Bloom kemudiannya telah ditambahbaik oleh Lorin Anderson pada tahun 1994 dengan mengubah kata kunci daripada kata nama kepada kata kerja pada aras domain kognitif tersebut sesuai dengan perubahan zaman. Semakan semula Taksonomi Bloom 2001 menyatakan dua aras terendah dalam aras tersebut iaitu mengingat dan memahami merupakan kemahiran berfikiran aras rendah atau KBAR manakala empat lagi aras yang tertinggi iaitu mengaplikasikan, menganalisis, menilai dan mencipta merupakan peringkat kemahiran berfikir aras tinggi atau KBAT. Proses berfikir dan komunikasi dalam penyelesaian masalah juga merupakan salah satu daripada enam fokus yang ditekankan dalam KSSM (2014) dan perlu dikuasai oleh setiap pelajar agar mereka dapat bersaing di peringkat antarabangsa.

Sehubungan itu, sistem peperiksaan dan pentaksiran yang diguna pakai selama ini telah dirombak semula bagi meningkatkan fokus terhadap KBAT demi untuk menjamin kualiti pendidikan negara agar dapat bersaing di peringkat antarabangsa. Justeru, dalam usaha merealisasikan hasrat yang terkandung dalam Pelan Pembangunan Pendidikan Malaysia (PPPM 2013-2025), soalan berunsurkan KBAT telah diperkenalkan secara beransur-ansur mulai tahun 2014. Norasmahami et al. (2015) menyatakan pendapat bahawa elemen KBAT telah menjadi keutamaan dalam soalan peperiksaan. Kementerian Pendidikan Malaysia (2013) juga telah menambah nisbah soalan berunsurkan KBAT sebanyak 75 peratus dalam peperiksaan sumatif bagi mata pelajaran teras di peringkat Sijil Pelajaran Malaysia (SPM) dan 50 peratus bagi mata pelajaran elektif mulai tahun 2016.

Kemahiran berfikir telah diperkenalkan di peringkat sekolah-sekolah di Malaysia seawal tahun 1994 dengan memberi keutamaan kepada kemahiran berfikir secara kreatif dan kritis(KBKK). Seterusnya pada tahun 2013, kemahiran berfikir ini sekali lagi dibangkitkan dalam Pelan Pembangunan Pendidikan Malaysia(PPPM) 2013 sehingga 2025 sebagai usaha untuk mentransformasikan sistem pendidikan negara. Kedua-dua langkah ini bertujuan untuk menyediakan generasi pelajar yang berkualiti dari segala aspek sesuai dengan perubahan pada abad ke-21. Pelajar yang telah menguasai kemahiran berfikiran aras tinggi(KBAT) diharapkan agar mampu membuat penyelesaian masalah dan keputusan dengan lebih efektif untuk diri sendiri, masyarakat mahupun negara (Sukiman et al. 2012).

\section{Pernyataan Masalah}

KBAT yang telah dilaksanakan di seluruh negara dan diperhebat lagi mulai tahun 2014 turut menimbulkan beberapa isu dan kekangan untuk direalisasikan. Salah satunya, ialah tahap penguasaan KBAT pelajar Malaysia masih pada tahap yang rendah berdasarkan indikator Trends in International Mathematics \& Science Study (TIMSS) dan Programme for International Student Assessment (PISA). Laporan ini dibentangkan oleh Perunding Kestrel Education (UK) dan $21^{\text {st }}$ Century Schools (USA) 


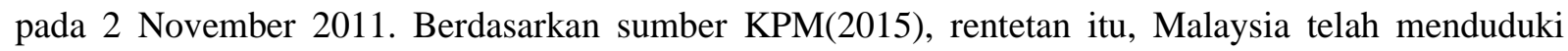
tempat ke-55 dalam penilaian kemahiran bacaan bagi ujian PISA pada tahun 2014. Justeru, adalah penting untuk mengetahui sama ada sikap dan motivasi pelajar terhadap KBAT dalam pembelajaran mempengaruhi tahap pengetahuan dan penguasaan mereka. Fokus kajian mengenai pembelajaran Bahasa Iban ini dipilih memandangkan kajian dalam subjek ini masih kurang dilaksanakan. Pemilihan subjek elektif atau tambahan yakni Bahasa Iban ini dikaji untuk mengangkat martabat bahasa ibunda sebagai salah satu medium pembelajaran yang tidak kurang penting dalam membentuk kejayaan seseorang pelajar.

Kajian lepas telah mendapati bahawa terdapat beberapa masalah yang timbul dalam pelaksanaan KBAT di sekolah. Antaranya adalah sikap dan teknik pengajaran guru itu sendiri. Kajian Zamri dan Nor Razah (2011) mendapati bahawa guru lebih banyak menggunakan soalan aras rendah dalam PdPc. Perkara ini menyebabkan pelajar menjadi pasif, kurang inisiatif untuk berfikir lebih jauh, tidak kreatif dan bersikap sambil lewa. Selain itu, pelajar sudah terbiasa menerima dan menunggu jawapan, penerangan dan penyelesaian daripada guru kerana pendekatan konvensional ini sudah berakar umbi dalam amalan pengajaran kebanyakan guru. Faktor ini akan mempengaruhi sikap pelajar terhadap KBAT dalam pembelajaran sekali gus mencorakkan pencapaian mereka dalam pelajaran.

Zamri (2014) kemudiannya menyatakan bahawa PdPc yang berfokus kepada peperiksaan akan menyebabkan usaha untuk melahirkan pelajar yang seimbang seperti yang dihasratkan dalam Falsafah Pendidikan Kebangsaan(FPK) sukar direalisasikan. Tumpuan ini memberi penekanan kepada penyediaan maklumat yang bertujuan untuk mempersiapkan pelajar menduduki peperiksaan dan belajar sehingga sukatan pelajaran selesai. Oleh sebab itu, guru lebih cenderung mengajar menggunakan kaedah konvensional kerana mahu menghabiskan silibus pelajaran, menjimatkan masa, dan memudahkan kawalan pelajar. Pelajar pula belajar dengan tujuan mendapatkan keputusan yang cemerlang semata-mata dan tidak mengamalkan pembelajaran yang diperoleh di dalam kelas. Hal ini menyebabkan pelajar kurang menggunakan KBAT lantaran lebih banyak menghafal dan mengingat supaya dapat menjawab soalan peperiksaan sahaja.

Justeru, kajian ini bertujuan untuk mengenal pasti sikap pelajar terhadap KBAT dalam pembelajaran Bahasa Iban berdasarkan faktor jantina, bangsa dan sekolah. Selain itu, kajian ini juga bertujuan mengenal pasti hubungan antara motivasi intrinsik dan motivasi ekstrinsik dengan sikap pelajar terhadap KBAT dalam pembelajaran Bahasa Iban. Objektif kajian diperincikan seperti di bawah ini:

i. Mengenal pasti perbezaan sikap pelajar terhadap KBAT dalam pembelajaran Bahasa Iban berdasarkan faktor jantina.

ii. Mengenal pasti perbezaan sikap pelajar terhadap KBAT dalam pembelajaran Bahasa Iban berdasarkan faktor bangsa.

iii. Mengenal pasti perbezaan sikap pelajar terhadap KBAT dalam pembelajaran Bahasa Iban berdasarkan faktor sekolah

iv. Mengenal pasti hubungan antara motivasi intrinsik, motivasi ekstrinsik dengan sikap pelajar terhadap KBAT dalam pembelajaran Bahasa Iban.

\section{Sorotan Literatur}

Beberapa kajian lepas menunjukkan bahawa KBAT dalam kalangan pelajar ini dipengaruhi oleh banyak faktor. Pelbagai pendekatan dan strategi juga telah dikenal pasti untuk memastikan amalan KBAT terus diterapkan dalam PdPc di seluruh sekolah di negara ini. Tahap kesediaan guru dan persepsi pelajar terhadap KBAT juga telah dikaji bagi menentukan perkara dan langkah yang boleh diambil untuk menggiatkan lagi penerapan KBAT kepada pelajar dengan lebih berkesan. Noor dan Leong (2019) menyatakan bahawa minat yang terdapat dalam diri pelajar akan menggalakkan mereka mempelajari sesuatu perkara dengan lebih mendalam. Rahil (1995) pula mendapati bahawa pencapaian dan prestasi pelajar dapat ditingkatkan melalui sikap yang positif terhadap pembelajaran.

Selain itu, Mohamad Shukri (2016) juga telah mengkaji gaya pembelajaran dan KBAT dalam kalangan pelajar teknikal. Dalam kajian beliau mendapati bahawa terdapat hubungan yang signifikan di antara 
pola pembelajaran Kolb dan Marzano dengan KBAT pelajar teknik. Dalam kajian kedua yang dijalankan oleh Chew dan Zul Hazmi pada tahun 2018 pula memberi fokus kepada teknik dalam pengajaran dan pemudahcaraan yang menggunakan teknik penyoalan. Dapatan kajian beliau mendapati kekerapan guru-guru Bahasa Melayu mengaplikasikan teknik penyoalan KBAT berada pada tahap yang tinggi. Kajian beliau ini menyatakan bahawa usaha dan langkah pihak berkaitan seperti Kementerian Pelajaran Malaysia melalui Lembaga Peperiksaan, Bahagian Teknologi Pendidikan dan Bahagian Buku Teks perlu dipergiatkan untuk membantu penguasaan KBAT para pelajar. Pekara ini akan menjadikan pelajar biasa dengan KBAT dan boleh mengaplikasikannya ke dalam kehidupan sebenar.

Vinogharri (2016) pula mendapati penerapan strategi pengutaraan masalah dapat meningkatkan KBAT dalam kalangan pelajar. Seterusnya, Ainun et al. (2017) menyatakan bahawa motivasi yang tinggi akan mendorong pelajar melibatkan diri dalam aktiviti PdPc di dalam kelas dan secara tidak langsung, ini akan meningkatkan pencapaian pelajar dalam sesuatu mata pelajaran. Mohd. et al. (2015) pula menyatakan pelajar akan lebih bersikap positif terhadap sesuatu yang diminatinya dan ini membangkitkan rasa seronok hingga mereka terdorong untuk berusaha lebih gigih dalam mencapai matlamat dan seterusnya memperoleh gred A.

Nadzalinda (2015) pula melihat aspek tahap penguasaan, sikap dan minat pelajar Kolej Kemahiran Tinggi MARA terhadap mata pelajaran Bahasa Inggeris dalam kajian beliau. Dalam kerangka konsep, beliau menekankan sikap dan minat sebagai pemboleh ubah tidak bersandar yang mempengaruhi penguasaan pelajar dalam Bahasa Inggeris dan didapati minat mempunyai pengaruh yang lebih besar berbanding sikap. Sementara itu, Mohammad et al. (2018) yang telah mengkaji motivasi pelajar terhadap pembelajaran Bahasa Arab mendapati bahawa motivasi yang tinggi menyebabkan pelajar berminat untuk mempelajari mata pelajaran tersebut meskipun tahap motivasi yang berbeza boleh mempengaruhi perbezaan pencapaian dalam kalangan pelajar.

Hasil kajian yang dijalankan oleh Magdelene (2008) tentang sikap pelajar terhadap mata pelajaran Bahasa Iban pula amat baik. Kajian beliau menunjukkan 90 peratus pelajar menyukai pembelajaran Bahasa Iban. Ini bermakna hanya 10 peratus sahaja pelajar yang mempunyai sikap negatif terhadap mata pelajaran ini. Walau bagaimanapun, kajian beliau hanya tertumpu kepada pelajar sekolah rendah dan dapatan mungkin berbeza dengan kajian yang dijalankan di sekolah menengah khususnya kajian yang memfokuskan kepada KBAT dalam pembelajaran Bahasa Iban.

\section{Sikap terhadap KBAT}

Sikap didefinisikan sebagai penilaian keseluruhan terhadap sesuatu objek berdasarkan kognitif, afektif, tingkah laku dan mempengaruhi sesuatu tindakan (Maio \& Haddock, 2009). Sementara itu, Philip (2007) menyatakan sikap merupakan satu bentuk perlakuan, perasaan atau pemikiran dan selari dengan pernyataan. Azizi et al. (2005), Bohner dan Wanke (2002), Mensah dan Kuranchie (2013) pula memberikan definisi sikap sebagai suatu rangsangan terhadap afektif, tingkah laku dan kognitif. Oleh itu, sikap tidak wujud secara terasing dalam diri seseorang tetapi saling berkaitan dengan komponenkomponen yang terdapat dalam diri individu tersebut (Noziati, 2017).

\section{Motivasi terhadap KBAT}

Menurut Crow dan Crow (1981), motivasi adalah suatu desakan yang menyebabkan manusia mengubah sikap, minat atau kegiatannya. Kimble (1984) pula menyatakan bahawa motivasi merupakan proses dalam diri seseorang individu yang mewujudkan tujuan dan memberikan tenaga bagi tingkah laku seseorang. Tujuan dan tenaga inilah yang menjadi daya penggerak untuk melakukan aktiviti-aktiviti tertentu demi mencapai suatu matlamat. Secara ringkasnya, motivasi adalah penggerak kepada kemahuan dan keinginan seseorang individu untuk mencapai atau mendapatkan sesuatu. Menurut Mok (2011), terdapat dua aspek motivasi secara umumnya dan juga diambil kira dalam kajian ini iaitu motivasi intrinsik dan motivasi ekstrinsik. 
Motivasi intrinsik adalah motivasi yang berpunca daripada individu itu dan dikenali sebagai motivasi dalaman yang boleh wujud secara semula jadi atau boleh dibina melalui pembelajaran dan pengalaman. Pelajar yang cenderung memiliki motivasi intrinsik lebih menyukai tugasan yang mencabar. Terdapat beberapa faktor yang mempengaruhi motivasi intrinsik dalam pembelajaran termasuklah persepsi kebolehan, persepsi kawalan iaitu berkaitan dengan usaha pelajar, perasaan terhadap pembelajaran dan bimbingan guru di mana pelajar bertanggungjawab membuat keputusan dan menggunakan cara mereka sendiri dalam melakukan sesuatu aktiviti atau tugasan.

Motivasi ekstrinsik pula bermaksud motivasi yang wujud daripada luaran iaitu dorongan kepada pelajar untuk membuat sesuatu bagi memperoleh ganjaran. Motivasi ini bagaimanapun merupakan ganjaran yang jelas dan nyata seperti gred, markah, agregat, pujian, penghargaan, persaingan dan persekitaran pembelajaran yang kondusif serta menarik. Tujuan motivasi ekstrinsik ini ialah mendorong orang lain untuk melakukan sesuatu tindakan yang akan memberi manfaat kepadanya. Motivasi ekstrinsik yang bersifat sederhana seperti peneguhan positif iaitu pujian dan juga peneguhan negatif seperti sindiran, kritikan dan kemarahan boleh memberi kesan kepada tingkah laku pelajar.

\section{Kemahiran Berfikir Aras Tinggi(KBAT)}

KPM(2013) menyatakan KBAT sebagai keupayaan menerapkan pengetahuan, kemahiran dan nilai dalam membuat penaakulan dan refleksi bagi menyelesaikan masalah, membuat keputusan, berinovasi dan berupaya mencipta sesuatu yang baru. Menurut Rajendran (2014) pula, KBAT ialah suatu proses kognitif yang melibatkan aras tertinggi. Ia melibatkan proses mengaitkan maklumat baru dengan maklumat sedia ada, proses penyusunan maklumat mengikut hierarki kesusahan, menganalisis dan seterusnya membuat keputusan jika perlu.

\section{Bahasa Iban}

Bahasa Iban adalah bahasa ibunda kepada masyarakat yang berbangsa Iban dan merupakan mata pelajaran yang ditawarkan di kebanyakan sekolah di negeri Sarawak. Mata pelajaran ini telah ditawarkan sebagai mata pelajaran tambahan di 675 buah sekolah rendah dan 79 buah sekolah menengah. Di peringkat menengah atas, Bahasa Iban ditawarkan sebagai mata pelajaran elektif(Jabatan Pendidikan Negeri Sarawak, 2019). Walau bagaimanapun, tidak semua sekolah menawarkan mata pelajaran ini di sekolah khususnya jika sekolah tersebut bukan berada dalam populasi bangsa Iban.

\section{Metod Kajian}

Kajian ini dilaksanakan sepenuhnya menggunakan reka bentuk kajian kuantitatif dengan kaedah tinjauan. Justeru, kaedah ini melibatkan pentadbiran borang soal selidik terhadap responden yang telah dipilih secara rawak dari kalangan pelajar yang mengambil mata pelajaran Bahasa Iban sebagai sampel kajian. Populasi kajian ini melibatkan para pelajar yang mengambil mata pelajaran Bahasa Iban di daerah Simunjan, Sarawak. Terdapat empat buah sekolah menengah di daerah Simunjan yang menawarkan Bahasa Iban sebagai mata pelajaran tambahan dan elektif. Saiz sampel pula ditentukan secara rawak berdasarkan penentuan saiz sampel Krejcie dan Morgan (1970) di mana seramai 240 orang pelajar daripada 648 orang jumlah keseluruhan pelajar Tingkatan Satu hingga Tingkatan Lima yang mengambil mata pelajaran Bahasa Iban sekolah menengah di daerah yang dikaji telah menjadi responden.

Untuk mendapatkan maklumat yang diperlukan serta bersesuaian dengan tujuan dan hipotesis kajian, satu set instrumen telah dibina berdasarkan adaptasi dan modifikasi daripada beberapa soal selidik terdahulu. Bagi Bahagian A, pengkaji membina sendiri item berdasarkan pemboleh ubah yang hendak dikaji. Bagi konstruk Bahagian B iaitu berkaitan dengan sikap pelajar terhadap KBAT dalam pembelajaran Bahasa Iban, pengkaji telah mengadaptasi dan mengubah suai soal selidik kajian yang dijalankan oleh Tuan Rahayu, Mohd. Aderi dan Mohd. Isa (2017) yang mengkaji tentang pengetahuan, sikap dan kesediaan murid terhadap KBAT dalam mata pelajaran Tasawwur Islam. Sementara itu, 
DOI: https://doi.org/10.47405/mjssh.v6i6.833

konstruk Bahagian C iaitu konstruk motivasi intrinsik dan motivasi ekstrinsik pula telah diadaptasi dan diubahsuai daripada borang soal selidik Matei dan Abrudan (2015) yang mengkaji tentang hubungan motivasi intrinsik dan ekstrinsik terhadap prestasi pelajar. Terdapat tiga perkara yang perlu dijawab oleh responden dalam Bahagian A iaitu jantina, kaum dan sekolah. Bahagian B, C(i) dan C (ii) pula masing-masing mengandungi lapan item. Penilaian tahap sikap dan motivasi ini dilihat berdasarkan skala likert empat mata iaitu 1=Sangat Tidak Setuju, 2=Tidak Setuju, 3=Setuju dan 4=Sangat Setuju.

Secara amnya, dapatan kajian dianalisis menggunakan analisis statistik deskriptif dan statistik inferensi. Analisis deskriptif digunakan bagi menjelaskan data demografi responden seperti jantina, bangsa dan sekolah dalam nilai peratus dan frekuensi. Analisis statistik deskriptif juga digunakan untuk mendapatkan data mengenai sikap dan motivasi pelajar dan diinterpretasikan dalam frekuensi dan peratus. Seterusnya, dapatan nilai min untuk melihat perbezaan skor jantina, kaum dan sekolah akan diinterpretasikan kepada empat tahap seperti yang ditunjukkan dalam Jadual 1.

\section{Jadual 1: Interpretasi Skor Min untuk Tahap Sikap dan Motivasi}

\begin{tabular}{cc}
\hline Skor Min & Interpretasi \\
\hline $3.51-4.00$ & Tinggi \\
$2.51-3.50$ & Sederhana \\
$1.51-2.50$ & Rendah \\
$1.00-1.50$ & Kurang Kaitan \\
\hline
\end{tabular}

Sumber: Riduan (2012)

Sementara itu, analisis statistik inferensi pula digunakan untuk menguji ujian $\mathrm{t}$ bagi melihat perbezaan sikap pelajar terhadap KBAT berdasarkan faktor jantina. Ujian ANOVA satu hala pula digunakan untuk melihat perbezaan sikap pelajar terhadap KBAT berdasarkan faktor kaum dan sekolah manakala Ujian Korelasi melihat hubungan antara motivasi dengan sikap pelajar terhadap KBAT dalam pembelajaran Bahasa Iban. Kekuatan korelasi antara komponen atau pemboleh ubah pula diinterpretasikan seperti yang ditunjukkan dalam Jadual 2.

Jadual 2: Interpretasi Korelasi

\begin{tabular}{cc}
\hline Saiz Pekali Korelasi & Interpretasi/Kekuatan Hubungan $(\mathbf{r})$ \\
\hline $0.90-1.00$ & Sangat Kuat \\
$0.70-0.90$ & Kuat \\
$0.50-0.70$ & Sederhana Kuat \\
$0.30-0.50$ & Rendah \\
$0.01-0.30$ & Lemah \\
0 & Tiada Hubungan \\
\hline
\end{tabular}

Sumber: Hinkle, Wiersma dan Jurs (1998)

\section{Hasil Kajian}

Kajian ini melibatkan pelajar lelaki dan perempuan yang mengambil Bahasa Iban sebagai mata pelajaran elektif di sekolah menengah di daerah Simunjan. Jadual 3 di bawah menunjukkan keputusan analisis deskriptif iaitu profil demografi responden secara terperinci berdasarkan faktor jantina, kaum dan sekolah yang terlibat.

Hasil analisis statistik deskriptif menunjukkan 240 orang responden yakni pelajar Bahasa Iban di daerah Simunjan telah menjadi sampel kajian ini. Daripada jumlah tersebut, seramai 92 orang (38.3\%) adalah responden lelaki dan 148 orang $(61.7 \%)$ adalah responden perempuan. Dari segi demografi kaum, seramai 211 orang $(87.9 \%)$ responden adalah berbangsa Iban, 13 orang (5.4\%) responden berbangsa adalah Bidayuh, 10 orang (4.2\%) responden adalah berbangsa Cina dan 6 orang $(2.5 \%)$ responden merupakan lain-lain bangsa. Seterusnya dari segi sekolah yang terlibat pula, seramai 80 
DOI: https://doi.org/10.47405/mjssh.v6i6.833

orang (33.3\%) responden merupakan pelajar dari Sekolah A, 48 orang (20\%) responden dari Sekolah B, 55 orang (22.9\%) responden dari Sekolah C dan 57 orang (23.8\%) responden dari Sekolah D.

Jadual 3: Profil Demografi Responden Kajian

\begin{tabular}{lcc}
\hline Demografi & N (240) & Peratus (\%) \\
\hline Jantina: & 92 & 38.3 \\
Lelaki & 148 & 61.7 \\
Perempuan & & \\
Kaum: & 211 & 87.9 \\
Iban & 13 & 5.4 \\
Bidayuh & 10 & 4.2 \\
Cina & 6 & 2.5 \\
Lain-lain & & \\
Sekolah terlibat: & 80 & 33.3 \\
Sekolah A & 48 & 20.0 \\
Sekolah B & 55 & 22.9 \\
Sekolah C & 57 & 23.8 \\
Sekolah D &
\end{tabular}

\section{Ho: Tidak terdapat perbezaan yang signifikan sikap pelajar terhadap KBAT dalam pembelajaran Bahasa Iban berdasarkan faktor jantina.}

Jadual 4 menunjukkan Ujian -t sampel bebas telah digunakan untuk membandingkan purata sikap terhadap KBAT antara pelajar lelaki $(n=92)$ dan perempuan $(n=147)$. Statistik Shapiro -Wilk menunjukkan andaian kenormalan dipatuhi. Ujian Levene juga tidak signifikan, maka varians diandaikan sama antara pelajar lelaki dan perempuan. Ujian -t adalah tidak signifikan $(1.82)=0.495$, $\mathrm{p}>0.05, \mathrm{~d}=2.86$ secara statistik. Keputusan kajian ini menunjukkan sikap pelajar lelaki dan perempuan terhadap penggunaan KBAT dalam pembelajaran Bahasa Iban tidak mempunyai perbezaan yang ketara. Sikap pelajar lelaki terhadap penggunaan KBAT dalam pembelajaran Bahasa Iban agak rendah $(M=25.07, S D=2.99)$ berbanding dengan sikap pelajar perempuan $(M=25.76, S D=2.77)$. Namun begitu, perbezaan min yang sangat kecil ini menunjukkan tidak terdapat perbezaan yang signifikan sikap pelajar terhadap KBAT dalam pembelajaran Bahasa Iban berdasarkan faktor jantina.

Jadual 4: Perbezaan Sikap Pelajar terhadap KBAT dalam Pembelajaran Bahasa Iban Berdasarkan Faktor Jantina

\begin{tabular}{lllllll}
\hline Jantina & N & Skor Min & $\begin{array}{l}\text { Sisihan } \\
\text { Piawai }\end{array}$ & DK & Nilai-t & $\begin{array}{l}\text { Tahap } \\
\text { Signifikan }\end{array}$ \\
\hline Lelaki & 92 & 25.07 & 2.99 & 238 & 1.82 & 0.495 \\
Perempuan & 147 & 25.76 & 2.77 & & & \\
\hline
\end{tabular}

\section{$H_{0}$ : Tidak terdapat perbezaan yang signifikan sikap pelajar terhadap KBAT dalam pembelajaran Bahasa Iban dalam kalangan pelajar berdasarkan faktor kaum.}

Berdasarkan Jadual 5, analisis varian satu hala (ANOVA) antara kumpulan digunakan untuk melihat kesan etnik sesuatu kaum terhadap sikap pelajar terhadap KBAT dalam pembelajaran Bahasa Iban. Penelitian statistik kepencongan, kurtosis dan Shapiro-Wilk menunjukkan andaian kenormalan disokong oleh setiap keadaan. Ujian Levene adalah tidak signifikan ( $>0.05)$ dan keputusan ini tidak memenuhi andaian kehomogenan varians. Ujian ANOVA adalah tidak signifikan di mana nilai $\mathrm{F}(3,235)=0.615, \mathrm{p}>0.05$ dan ETA kuasa dua $=0.235$. Ini bermakna tidak terdapat perbezaan yang signifikan skor min sikap pelajar terhadap KBAT dalam pembelajaran Bahasa Iban berdasarkan kaum mereka. Keputusan ujian ANOVA Satu Hala tersebut juga adalah tidak signifikan secara statistik dan 
DOI: https://doi.org/10.47405/mjssh.v6i6.833

perbezaan sebenar dalam skor min antara kumpulan agak kecil. Secara deskriptifnya, pelajar yang terdiri dari bangsa lain-lain mencatatkan $\mathrm{M}=26.67, \mathrm{SP}=3.08$ adalah lebih tinggi dari pelajar berbangsa Iban $(\mathrm{M}=25.40, \mathrm{SP}=2.86)$, Bidayuh $(\mathrm{M}=26.08, \mathrm{SP}=3.25)$ dan $\mathrm{Cina}(\mathrm{M}=25.80, \mathrm{SP}=2.74)$.

Jadual 5: Perbezaan Sikap Pelajar terhadap KBAT dalam Pembelajaran Bahasa Iban Berdasarkan Faktor Kaum

\begin{tabular}{lccr}
\hline $\begin{array}{l}\text { Sikap pelajar terhadap KBAT dalam } \\
\text { pembelajaran Bahasa Iban }\end{array}$ & N & Skor Min & $\begin{array}{r}\text { Sisihan } \\
\text { Piawai }\end{array}$ \\
\hline Iban & 211 & 25.40 & 2.86 \\
Bidayuh & 13 & 26.08 & 3.25 \\
Cina & 10 & 25.80 & 2.74 \\
Lain-lain & 6 & 26.67 & 3.08 \\
\hline
\end{tabular}

\begin{tabular}{lccccc}
\hline $\begin{array}{l}\text { Sikap pelajar terhadap KBAT } \\
\text { dalam pembelajaran Bahasa } \\
\text { Iban }\end{array}$ & $\begin{array}{c}\text { Jumlah } \\
\text { Kuasa Du: }\end{array}$ & $\begin{array}{c}\text { Darjah } \\
\text { Kebebasan }\end{array}$ & $\begin{array}{c}\text { Min Kuasa } \\
\text { Dua }\end{array}$ & Nilai F & Signifikan \\
\hline Antara kumpulan & 15.27 & 3 & 5.09 & .615 & .606 \\
Dalam Kumpulan & 1946.45 & 235 & 8.28 & & \\
Total & 1961.72 & 238 & & & \\
\hline
\end{tabular}

\section{$H_{o}$ : Tidak terdapat perbezaan yang signifikan sikap pelajar terhadap KBAT dalam pembelajaran Bahasa Iban berdasarkan faktor sekolah.}

Berdasarkan Jadual 6, analisis varian satu hala (ANOVA) antara kumpulan digunakan untuk melihat kesan faktor sekolah yang diwakili terhadap sikap pelajar terhadap KBAT dalam pembelajaran Bahasa Iban. Penelitian statistik kepencongan, kurtosis dan Shapiro-Wilk menunjukkan andaian kenormalan disokong oleh setiap keadaan. Ujian Levene adalah tidak signifikan ( $>0.05)$ dan keputusan ini tidak memenuhi andaian kehomogenan varians. Ujian ANOVA adalah tidak signifikan dengan nilai $\mathrm{F}(3$, 236) $=0.238 ; \mathrm{p}>0.05$ dan ETA kuasa dua $=0.236$.

Secara deskriptifnya, pelajar yang bersekolah di SMK B $(\mathrm{M}=3.22, \mathrm{SP}=0.37)$ mempunyai sikap terhadap KBAT yang lebih tinggi berbanding pelajar dari sekolah SMK A (M=3.19, SP=0.33), sekolah SMK C $(\mathrm{M}=3.18, \mathrm{SP}=0.37)$ dan sekolah SMK D $(\mathrm{M}=3.16, \mathrm{SP}=0.38)$. Ini bermakna tidak terdapat perbezaan yang signifikan skor sikap pelajar terhadap KBAT dalam pembelajaran Bahasa Iban berdasarkan faktor sekolah.

Jadual 6 : Perbezaan Sikap Pelajar terhadap KBAT dalam Pembelajaran Bahasa Iban Berdasarkan Faktor Sekolah

\begin{tabular}{|c|c|c|c|c|c|}
\hline \multicolumn{2}{|c|}{$\begin{array}{l}\text { Sikap pelajar terhadap KBAT dalam } \\
\text { pembelajaran Bahasa Iban }\end{array}$} & $\mathbf{N}$ & \multicolumn{2}{|r|}{ Skor Min } & $\begin{array}{l}\text { Sisihan } \\
\text { Piawai }\end{array}$ \\
\hline SMK A & & 80 & & 3.19 & .33 \\
\hline SMK B & & 48 & & 3.22 & .37 \\
\hline SMK C & & 55 & & 3.18 & .37 \\
\hline SMK D & & 57 & & 3.16 & .38 \\
\hline $\begin{array}{l}\text { Sikap pelajar terhadap KBA } \\
\text { dalam pembelajaran Bahasa } \\
\text { Iban }\end{array}$ & $\begin{array}{c}\text { Jumlah } \\
\text { Kuasa Du: }\end{array}$ & $\begin{array}{c}\text { Darjah } \\
\text { Kebebasan }\end{array}$ & $\begin{array}{l}\text { Min Kuaš } \\
\text { Dua }\end{array}$ & Nilai F & Signifikan \\
\hline Antara kumpulan & .092 & 3 & .031 & .238 & .870 \\
\hline Dalam Kumpulan & 30.56 & 236 & .129 & & \\
\hline Total & 30.65 & 239 & & & \\
\hline
\end{tabular}




\section{$H_{o}$ : Tidak terdapat hubungan signifikan antara motivasi intrinsik dan motivasi ekstrinsik dengan sikap pelajar terhadap KBAT dalam pembelajaran Bahasa Iban.}

Analisis korelasi Pearson telah digunakan untuk melihat hubungan di antara motivasi intrinsik dan motivasi ekstrinsik dengan sikap pelajar terhadap KBAT dalam pembelajaran Bahasa Iban. Berdasarkan Jadual 7, hubungan motivasi intrinsik dengan sikap pelajar terhadap KBAT dalam pembelajaran Bahasa Iban mencatatkan hubungan positif yang signifikan di mana $r=0.89, p<0.05$. Oleh itu, hipotesis yang menyatakan tidak terdapat hubungan yang signifikan antara motivasi intrinsik dengan sikap terhadap KBAT dalam pembelajaran Bahasa Iban adalah ditolak. Keputusan ini juga menunjukkan hubungan positif yang kuat antara motivasi intrinsik dengan sikap pelajar terhadap KBAT dalam pembelajaran Bahasa Iban. Hasil kajian juga menunjukkan terdapat hubungan yang signifikan antara motivasi intrinsik dengan sikap terhadap KBAT dalam pembelajaran Bahasa Iban di mana $\mathrm{p}=0.00$. Hubungan linear ini dapat dirumuskan sebagai semakin tinggi motivasi intrinsik pelajar makin tinggi sikap KBAT pelajar terhadap mata pelajaran Bahasa Iban.

Seterusnya, hasil keputusan kajian ini menunjukkan bahawa hubungan motivasi ekstrinsik juga mencatatkan hubungan positif $(\mathrm{r}=0.69, \mathrm{p}<0.05)$ yang signifikan dengan sikap pelajar terhadap KBAT dalam pembelajaran Bahasa Iban. Ini menunjukkan hipotesis yang menyatakan tidak terdapat hubungan antara motivasi ekstrinsik dengan sikap terhadap KBAT dalam pembelajaran Bahasa Iban adalah ditolak. Keputusan ini menunjukkan terdapat hubungan linear yang signifikan antara motivasi ekstrinsik dengan sikap terhadap KBAT dalam pembelajaran Bahasa Iban. Walau bagaimanapun, hubungan ini adalah hubungan positif sederhana.

Jadual 7: Korelasi antara Motivasi Intrinsik, Ekstrinsik dan Sikap Pelajar terhadap KBAT dalam Pembelajaran Bahasa Iban

\begin{tabular}{lccc}
\hline & $\begin{array}{c}\text { Motivasi } \\
\text { intrinsik }\end{array}$ & Motivasi ekstrins & $\begin{array}{c}\text { Sikap terhadap } \\
\text { KBAT }\end{array}$ \\
\hline Sikap terhadap KBAT & 0.887 & 0.687 & \\
Motivasi intrinsik & & 0.719 & 0.887 \\
Motivasi ekstrinsik & & & 0.687
\end{tabular}

* Aras ke-ertian $\alpha=0.05$

\section{Perbincangan Kajian}

Berdasarkan dapatan kajian mengenai sikap dan motivasi pelajar terhadap KBAT dalam pembelajaran Bahasa Iban, didapati bahawa tidak terdapat perbezaan yang signifikan sikap pelajar lelaki dan pelajar perempuan terhadap KBAT dalam pembelajaran Bahasa Iban. Ini bermakna, jantina tidak mempengaruhi sikap pelajar terhadap KBAT dalam pembelajaran Bahasa Iban. Skor min yang ditunjukkan dalam dapatan pula menjelaskan bahawa min sikap pelajar lelaki adalah lebih kecil berbanding pelajar perempuan di mana pelajar lelaki mencatatkan min 25.07 dan pelajar perempuan mencatatkan min 25.75. Meskipun perbezaan ini kecil dan tidak signifikan tetapi jelas menunjukkan bahawa pelajar perempuan cenderung bersikap lebih positif terhadap KBAT. Dapatan ini selari dengan kajian yang dijalankan oleh Nasyimah Ismail dan Zamri Mahamod (2016) yang mengkaji sikap dan kesedaran pelajar sekolah menengah terhadap KBAT dalam pembelajaran Komsas Bahasa Melayu. Kajian mereka mendapati bahawa tidak terdapat perbezaan sikap terhadap KBAT berdasarkan jantina pelajar.

Begitu juga dari aspek kaum pelajar di mana dapatan menunjukkan tidak terdapat perbezaan yang signifikan skor min sikap pelajar terhadap KBAT dalam pembelajaran Bahasa Iban berdasarkan faktor kaum. Walau bagaimanapun, pelajar berbangsa Iban mencatatkan skor min KBAT yang lebih rendah berbanding bangsa lain-lain, Bidayuh dan juga Cina. Dapatan ini juga menunjukkan walaupun pelajar itu menggunakan bahasa ibundanya, tidak semestinya sikap pelajar terhadap KBAT dalam pembelajaran bahasa tersebut positif. Perkara ini menjadi persoalan memandangkan Bahasa Iban 
adalah bahasa ibunda pelajar berbangsa Iban itu sendiri. Punca dan faktor yang menyebabkan pelajar berbangsa Iban mempunyai sikap terhadap KBAT yang lebih rendah berbanding bangsa Bidayuh, Cina dan lain-lain haruslah tidak diabaikan memandangkan mata pelajaran yang dikaji ini adalah bahasa ibunda pelajar Iban itu sendiri. Justeru, kajian akan datang diharap dapat merungkai punca dan faktor kepada dapatan ini.

Faktor seperti persepsi terhadap bahasa ibunda dan peranan guru dalam mendorong pelajar untuk menggunakan KBAT dalam pembelajaran juga perlu diambil kira terutamanya dalam memupuk motivasi pelajar. Ini kerana motivasi merupakan faktor yang sangat penting untuk menentukan sikap mereka terhadap pembelajaran menggunakan KBAT ini. Pihak guru juga perlu kreatif dalam menyediakan material-material yang mampu mencetuskan minat pelajar untuk mempelajari Bahasa Iban dengan lebih mendalam dan sekali gus mengaplikasikan KBAT di dalam kehidupan mereka. Hasil kajian ini adalah sama dengan kajian oleh Mohammad et al.(2018) yang mendapati bahawa kaedah pengajaran yang pelbagai boleh membantu pelajar memahami sesuatu pengetahuan dan kemahiran yang disampaikan dengan lebih cepat sekaligus ia juga mampu membantu guru memupuk motivasi pelajar dalam mempelajari Bahasa Iban.

Dapatan juga menunjukkan tidak terdapat perbezaan yang signifikan skor min sikap pelajar terhadap KBAT dalam pembelajaran Bahasa Iban berdasarkan faktor sekolah di daerah Simunjan. Hal ini kerana sistem pengajaran dan kurikulum yang diguna pakai oleh kesemua sekolah adalah sama. Pengkaji juga mendapat tahu bahawa sekolah menengah di daerah yang dikaji sememangnya mengamalkan perkongsian ilmu dan penyelarasan item pentaksiran atau instrumen peperiksaan khususnya melibatkan kelas peperiksaan dan menengah atas. Selain itu, keempat-empat sekolah yang dikaji juga sering menerima lawatan dan bimbingan daripada pihak PPD seperti School Improvement Specialist Coaches(SISC+). Walau bagaimanapun, pendekatan pengajaran yang diamalkan oleh guru mungkin menjadi antara faktor yang boleh mempengaruhi sedikit perbezaan skor min antara sekolah. Kenyataan ini disokong oleh Mohammad et al. (2018) yang berpendapat bahawa kaedah pengajaran yang pelbagai boleh membantu pelajar memahami sesuatu pengetahuan dan kemahiran yang disampaikan dengan lebih cepat.

Secara keseluruhannya, terdapat hubungan yang signifikan antara motivasi intrinsik dan ekstrinsik dengan sikap terhadap KBAT dalam pembelajaran Bahasa Iban di mana kedua-dua aspek ini saling berkaitan dalam mempengaruhi KBAT pelajar. Mohammad et al. (2018) dalam kajian mereka berpendapat bahawa pelajar yang mempunyai nilai intrinsik yang tinggi akan sedaya upaya berusaha untuk menguasai pelajaran yang memberi cabaran dan kepuasan kepadanya yakni penerapan KBAT dalam pembelajaran Bahasa Iban. Abdul et al. (2015) juga melaporkan dalam kajian mereka bahawa terdapat banyak faktor yang mempengaruhi minat pelajar terhadap pengajaran dan pembelajaran di dalam kelas seperti kesedaran diri pelajar dan tahap kesukaran isi kandungan mata pelajaran. Sebahagian pelajar yang bermotivasi tinggi tentunya berasa teruja untuk menjawab soalan-soalan yang sukar manakala pelajar yang kurang bermotivasi akan merasakan soalan-soalan tersebut sukar dijawab lantas menjawab dengan sambil lewa atau hanya membiarkan soalan tersebut kosong tanpa jawapan. Dari sudut ekstrinsik pula, terdapat banyak faktor yang membangkitkan motivasi dan seterusnya mempengaruhi sikap pelajar terhadap pembelajaran. Matei dan Abruden (2015) juga mendapati bahawa motivasi intrinsik dan motivasi ekstrinsik mempunyai hubungan yang positif terhadap pencapaian pelajar di universiti.

Kajian ini diharapkan dapat membuka peluang kepada para pengkaji akan datang khususnya yang ingin mengkaji KBAT mahupun pembelajaran Bahasa Iban dengan lebih lanjut. Banyak isu berkaitan dengan KBAT dan pembelajaran Bahasa Iban yang perlu diketengahkan dan dirungkai agar penambahbaikan pengajaran dan amalan pembelajaran dapat dilaksanakan secara berterusan. Salah satu daripada cadangan kajian lanjutan adalah memperluaskan lagi skop kajian dengan mengambil kira populasi yang lebih besar. Pengkaji akan datang boleh membuat kajian yang melibatkan seluruh sekolah yang menawarkan mata pelajaran Bahasa Iban di negeri Sarawak. Selain daripada kajian yang berfokus kepada pelajar yang mengambil mata pelajaran ini, pengkaji akan datang juga boleh melihat dari sudut guru-guru yang mengajar Bahasa Iban baik di sekolah rendah mahupun di sekolah menengah. 
Dari aspek pemboleh ubah kajian pula, pengkaji akan datang diharapkan dapat mengkaji beberapa pemboleh ubah lain selain daripada sikap dan motivasi. Sebagai contoh, kajian tentang budaya hidup, tradisi, linguistik, puisi, kepercayaan dan seumpamanya boleh dibuat agar lebih banyak kajian mengenai bangsa Iban diterbitkan dan boleh dijadikan rujukan. Kajian-kajian tersebut kemudiannya akan menjadi dorongan dan motivasi kepada pengkaji lain selain daripada menyediakan bahan rujukan yang boleh digunakan oleh para ahli akademik.

Bagi mendapatkan keputusan kajian yang lebih terperinci dan mendalam, pengkaji akan datang juga boleh menjalankan kajian secara kualitatif ataupun menggunakan kaedah gabungan kuantitatif dan kualitatif. Melalui kaedah ini, persoalan yang diajukan dalam kajian akan cenderung bersifat terbuka dan kompleks dengan pelbagai aspek di mana setiap persoalan dapat dikaji dengan lebih baik (Shema dan Woodman, 2013). Melalui pendekatan kualitatif juga, data kajian akan lebih bermakna kerana dilihat secara lebih mendalam melalui pengalaman dan pandangan responden. Gabungan kaedah kajian tentunya menunjukkan kesungguhan usaha pengkaji dalam memperoleh kesahihan data seterusnya memberikan impak positif kepada pengkaji dan dapatan kajiannya.

\section{Kesimpulan}

Secara kesimpulannya, sikap dan motivasi terhadap KBAT perlu diterapkan agar pelajar dapat mengoptimumkan penggunaan minda sekali gus mengaplikasikan pengetahuan dan kemahiran dalam kehidupan. Justeru, adalah perlu untuk menerapkan KBAT kepada para pelajar sejak dari awal persekolahan lagi agar kemahiran berfikir dan bertindak menggunakan KBAT menjadi amalan berterusan. Pelajar yang merupakan teraju kepimpinan akan menentukan hala tuju negara kemudian hari perlu dilatih dan dididik dengan pelbagai kemahiran yang dapat merangsang perkembangan afektif, psikomotor dan juga intelek.

Walau bagaimanapun, amalan KBAT ini tidak dapat dicapai jika pelajar tidak memiliki motivasi dan sikap yang positif terhadap pembelajaran. Pembelajaran mata pelajaran bahasa ibunda yakni Bahasa Iban pula tidak harus diketepikan kerana bahasa ibunda yang menjadi bahasa pertuturan seharian pelajar seharusnya menjadi dorongan dan kelebihan kepada pelajar untuk mencapai kecemerlangan akademik. Justeru, mata pelajaran Bahasa Iban yang merupakan salah satu bahasa ibunda etnik terbesar di negeri Sarawak ini diharapkan agar terus berkembang dan menjadi antara bahasa yang mempunyai nilai ilmiah yang tinggi demi mengangkat martabat bangsanya.

\section{Rujukan}

Abdul Halim Mohamad \& Wan Muhamad Wan Sulong. (2016). Minat dan Sikap Pelajar Bacelor Bahasa Arab di IPTA Malaysia Terhadap Bahasa Arab. Jurnal Al-Anwar, Persatuan Bekas Mahasiswa Islam Timur Tengah(PBMITT), l(1).

Ainun Rahmah Iberahim, Zamri Mahamod \& Wan Muna Ruzanna Wan Mohamad. (2017). Pembelajaran Abad ke-21 dan Pengaruhnya terhadap Sikap, Motivasi dan Pencapaian Bahasa Melayu Pelajar Sekolah Menengah. Jurnal Pendidikan Bahasa Melayu, 7(2): 77-88.

Azizi bin Yahaya \& Nurul Ain binti Hamsari. (2010). Teori-teori Motivasi. Universiti Teknologi Malaysia.

Bloom, B.S. (1956). Taxonomy of Educational Objectives, Handbook 1: The Cognitive Domain. New York: David McKay Co Inc.

Bohner, Gerd \& Micheale Wanke. (2002). Attitude and Attitude Change. New York:Phychology Press. 5-18

Chew, F. P., \& Zul, H. H. (2017). Kemahiran Berfikir Aras Tinggi dalam Pembelajaran dan Pemudahcaraan Bahasa Melayu Melalui Teknik Penyoalan. Jurnal Pendidikan Bahasa Melayu. Vol. 8, Bil. 1(Mei 2018):1-12

Crow, L. D. \& Crow, L. (1980). Psikologi Pendidikan Untuk Perguruan. Kuala Lumpur. Dewan Bahasa dan Pustaka. 
Maio, G. R. \& Haddock, G. (2010). The Psychology of Attitudes and Attitude Change. SAGE Publication Ltd.

Kementerian Pendidikan Malaysia. (2013). Pelan Pembangunan Pendidikan Malaysia 2013-2025. Putrajaya: Kementerian Pendidikan Malaysia.

Kimble, G. A. (1984). Psychology's two cultures. American Psychologist, 9, 833-839.

Krejcie, R.V. \& Morgan, D.W. (1970). Determing Sample Size For Research Activities. Educational Psychological Measurement. 30:608.

Lembaga Peperiksaan. (2013). Kemahiran Berfikir Aras Tinggi. Putrajaya: Kementerian Pendidikan Malaysia.

Magdeline Anak Nor. (2008). Sikap Pelajar terhadap Mata Pelajaran Bahasa Iban dan Pertaliannya dengan Gaya Pengajaran Guru. Kertas Projek Sarjana. Bangi: Universiti Pendidikan Malaysia.

Matei, M. C. \& Abrudan M. M. ( 2011). Intrinsic and Extrinsic Motivation: An Investigation of Performance Correlation on Students. University of Oradea.

Mensah, J. K., Okyere M., Kuranchie A. (2013). Student Attitude Towards Mathematics and Performance: Does the teacher attitude matter? Journal of Education and Practice, 4(3).

Mohammad Haafiz Ahmid, Mohd Khairuddin Abdullah \& Khalid Johari. (2018). Pengajaran Guru dan Kepercayaan Motivasi Pelajar dalam Pembelajaran Bahasa Arab di Sekolah Menengah. Malaysian Journal of Social Sciences and Humanities, 3(3): 1636-147.

Mohd Noor Badlishah Abdul Kadir, Mohd Mustaman Abdul Karim \& Nurulhuda Abd Rahman. (2015). Sikap Terhadap Pembelajaran Fizik dan Hubungannya dengan Pencapaian dalam Kalangan Pelajar Sains. Seminar Kebangsaan Pendidikan Negeri Kali ke-5.

Mohamad Shukri Ismail (2016). Gaya Pembelajaran dan Kemahiran Berfikir Aras Tinggi dalam kalangan Pelajar Teknikal. Universiti Tun Hussein Onn, Malaysia. Diakses dari http://eprints.uthm.edu.my/id/eprint/9074 pada 24 Januari 2021.

Mok, S. S. (2011). Nota Intisari Pendidikan Psikologi Pendidikan. Penerbitan Multimedia Sdn. Bhd. Selangor Darul Ehsan.

Nadzalinda Binti Kamsur. (2015). Tahap Penguasaan, Sikap dan Minat Pelajar Kolej Kemahiran Tinggi MARA terhadap Mata Pelajaran Bahasa Inggeris. Universiti Tun Hussein Onn.

Nasyimah Ismail \& Zamri Mahamod. (2015). Sikap dan Kesediaan Pelajar Sekolah Menengah Terhadap Kemahiran Berfikir Aras Tinggi dalam Pembelajaran Komsas Bahasa Melayu. Jurnal Pendidikan Bahasa Melayu-JPBM, 6(2): 5967

Noor Erma Binti Abu \& Leong K. W. (2014). Hubungan Antara Sikap, Minat, Pengajaran Guru dan Pengaruh Rakan Sebaya Terhadap Pencapaian Matematik Tambahan Tingkatan 4. JuKu: Jurnal Kurikulum \& Pengajaran Asia Pasifik, 2(1).

Norasmahani Nor, Nur Sofiah Suhaimi, Nur Syamira Abdul Wahab, Mohd Khushairi Che Ismail, Mohd Aderi Che Noh \& Khadijah Abdul Razak. (2015). Pelaksanaan KBAT dalam Pengajaran dan Pembelajaran Pendidikan Islam Sekolah Menengah: Satu Tinjauan di Putrajaya. Proceeding: 7th International on Regional Education.

Noziati Borhan. (2017). Model Kepecayaan, Sikap Dan Amalan Pengajaran Dalam Kalangan Guru Permulaan Matematik Bagi Sekolah Rendah Di Malaysia. (Tesis Ijazah Doktor Falsafah yang tidak diterbitkan). Fakulti Pendidikan. Universiti Kebangsaan Malaysia.

Philip G. A. \& Jane K. (2007). The Internationalization of Higher Education: Motivation and Realities. SAGE Journals

Rahil Mahyuddin. (1995). Asas Pendidikan 2: Psikologi dalam Bilik Darjah. Longman, Kuala Lumpur.

Rajendran N. S. (2013). Higher Order Thinking Skill. Universiti Pendidikan Sultan Idris. Tanjong Malim, Perak.

Shema T. \& Woodman, J. (2013). Using Mixed Methods In Health Research. Journal of The Royal Society and Medicine. 4(6). Diakses dari http://www.ncbi.nlm.nih.gov/pmc/ articles/PMC3697857/ pada 24 Januari 2021.

Sukiman Saad, Noor Shah Saad \& Mohd Uzi Abdullah. (2012). Pengajaran Kemahiran Berfikir Aras Tinggi:Persepsi dan Amalan Guru Matematik Semasa Pengajaran dan Pembelajaran di Bilik Darjah. Jurnal Pendidikan Sains \& Matematik Malaysia, 2(1): 18-36.

Tuan Rahayu Tuan Lasan, Mohd. Aderi Che Noh \& Mohd. Isa Hamzah. (2017). Pengetahuan, Sikap dan Kesediaan Murid Terhadap Kemahiran Berfikir Aras Tinggi(KBAT) dalam Mata Pelajaran Tasawwur Islam. Tinta Artikulasi Membina Ummah, 3(1). 
DOI: https://doi.org/10.47405/mjssh.v6i6.833

Vinogharri Munianndy, Johari Surif dan Nor Hasniza Ibrahim (2016). Penerapan Strategi Pengutaraan

Masalah untuk Meningkatkan Kemahiran Berfikir Aras Tinggi. Universiti Teknologi Malaysia.

Zamri Mahamod. (2014). Inovasi P\&P dalam pendidikan Bahasa Melayu. Cetakan Ketiga. Tanjung Malim: Penerbit Universiti Pendidikan Sultan Idris.

Zamri Mahamod \& Nor Razah Lim. (2011). Kepelbagaian Kaedah Penyoalan Lisan Dalam Pengajaran

Bahasa Melayu: Kaedah Pemerhatian. Jurnal Pendidikan Bahasa Melayu, 1(5): 51-65. 